\title{
A typology of time-scale mismatches and behavioral interventions to diagnose and solve conservation problems
}

\author{
Robyn S. Wilson, * D David J. Hardisty, † Rebecca S. Epanchin-Niell, $\ddagger$ Michael C. Runge, $\S$ \\ Kathryn L. Cottingham, ${ }^{* *}$ Dean L. Urban, $\nmid \dagger$ Lynn A. Maguire,$\dagger \dagger$ Alan Hastings, $\neq \ddagger$ Peter J. Mumby,, $\mathbb{S}$ \\ and Debra P.C. Peters ${ }^{* * *}$ \\ ${ }^{*}$ School of Environment and Natural Resources, The Ohio State University, 210 Kottman Hall, 2021 Coffey Road, Columbus, OH \\ 43221, U.S.A. \\ †Sauder School of Business, University of British Columbia, 2053 Main Mall, Vancouver, BC V6T 1Z2, Canada \\ $\ddagger$ Resources for the Future, 1616 P Street NW, Washington, D.C. 20036, U.S.A. \\ §U.S. Geological Survey, Patuxent Wildlife Research Center, 12100 Beech Forest Road, Laurel, MD 20708, U.S.A. \\ ** Department of Biological Sciences, Dartmouth College, 78 College Street, Hanover, NH 03755, U.S.A. \\ t†Nicholas School of the Environment, Duke University, Box 90328, Durham, NC 27708, U.S.A. \\ $\ddagger \ddagger$ Department of Environmental Science and Policy, University of California, Davis, CA 95616, U.S.A. \\ SSARC Centre for Excellence for Reef Studies and School of Biological Sciences, Townsville, Qld 4811, Australia \\ *** USDA Agricultural Research Service, Jornada Experimental Range, Las Cruces, NM 80003 U.S.A.
}

\begin{abstract}
Ecological systems often operate on time scales significantly longer or shorter than the time scales typical of human decision making, which causes substantial difficulty for conservation and management in socioecological systems. For example, invasive species may move faster than bumans can diagnose problems and initiate solutions, and climate systems may exbibit long-term inertia and short-term fluctuations that obscure learning about the efficacy of management efforts in many ecological systems. We adopted a managementdecision framework that distinguishes decision makers within public institutions from individual actors within the social system, calls attention to the ways socioecological systems respond to decision makers' actions, and notes institutional learning that accrues from observing these responses. We used this framework, along with insights from bedeviling conservation problems, to create a typology that identifies problematic timescale mismatches occurring between individual decision makers in public institutions and between individual actors in the social or ecological system. We also considered solutions that involve modifying human perception and behavior at the individual level as a means of resolving these problematic mismatches. The potential solutions are derived from the behavioral economics and psychology literature on temporal challenges in decision making, such as the buman tendency to discount future outcomes at irrationally bigh rates. These solutions range from framing environmental decisions to enbance the salience of long-term consequences, to using structured decision processes that make time scales of actions and consequences more explicit, to structural solutions aimed at altering the consequences of short-sighted behavior to make it less appealing. Additional application of these tools and long-term evaluation measures that assess not just behavioral changes but also associated changes in ecological systems are needed.
\end{abstract}

Keywords: decision theory, economics, psychology, socioecological systems, temporal lags

Una Tipología de Desigualdades en la Escala de Tiempo y de Intervenciones de Comportamiento para Diagnosticar y Solucionar Problemas de Conservación

Resumen: Los sistemas ecológicos comúnmente operan en escalas temporales que son significativamente más largas o más cortas que las de un proceso de toma de decisiones, lo que ocasiona una dificultad 
sustancial para la conservación y el manejo de sistemas socio-ecológicos. Por ejemplo, las especies invasoras pueden moverse más rápido de lo que los humanos podemos diagnosticar problemas e iniciar soluciones, y los sistemas climáticos pueden exhibir una inercia a largo plazo y fluctuaciones a corto plazo que compliquen la eficiencia de los esfuerzos de manejo en la mayoría de los sistemas ecologicos. Adoptamos un marco de trabajo de decisiones de manejo que distingue a quienes toman las decisiones dentro de las instituciones públicas de los actores individuales dentro del sistema social, atrae atención a la forma en la que los sistemas socio-ecológicos responden a las acciones de quienes toman las decisiones y da cuenta del aprendizaje institucional que se acumula con la observación de estas respuestas. Usamos este marco de trabajo, junto con conocimiento de los complejos problemas de conservación, para crear una tipología que identifique las desigualdades problemáticas en la escala de tiempo que ocurren entre quienes toman las decisiones en las instituciones públicas y los actores individuales en el sistema social o ecológico. También consideramos soluciones que involucren modificar la percepción y el comportamiento bumano a nivel individual como medio para resolver estas desigualdades problemáticas. Las soluciones potenciales se derivan de la literatura sobre economía conductual y psicología de los retos temporales en la toma de decisiones, como la tendencia bumana de discontinuar los resultados futuros a tasas irracionalmente altas. Estas soluciones van desde enmarcar las decisiones ambientales para mejorar la prominencia de las consecuencias a largo plazo hasta el uso de procesos de decisiones estructuradas que hagan que las escalas de tiempo de las acciones y las consecuencias sean más explícitas y soluciones estructurales enfocadas en la modificación de las consecuencias del comportamiento con poca visión del futuro para que este sea menos atractivo. Se requiere de la aplicación adicional de estas herramientas y de las medidas de evaluación a largo plazo que no sólo evalúan los cambios en el comportamiento sino también los cambios asociados en el sistema ecolóico.

Palabras Clave: disminuciones temporales, economía, psicología, sistemas socio-ecológicos, teoría de decisión

\section{Introduction}

Mismatched time scales among the endogenous dynamics of the socioecological system and human decision making, action, and learning are common features of conservation and environmental management failures (see Supporting Information for a discussion of the temporal lags in coupled systems that contribute to long-standing management challenges in 3 exemplar case studies: eutrophication, catastrophic wildfire, and invasive species). Time-scale challenges in socioecological systems have been discussed previously in diverse fields, including bioeconomics (Clark 2010), traditional environmental governance (Ostrom 1990), and, most recently, panarchy theory (Gunderson 2001). In seminal work on panarchy theory, Holling (2001) describes the complex scale interactions of nested socioecological systems, claiming that human foresight, communication, and technology can be used to overcome temporal and spatial mismatches (i.e., problems of fit) that generally lead to the collapse of otherwise functioning and adaptive complex systems (see also Cumming et al. 2006). Folke et al. (2007) note the pervasiveness of these challenges, again pointing to systems theory for understanding and to adaptive management for solutions. Guerrero et al. (2013) analyzed scale mismatches in the context of conservation planning, used a partial decision-analytic structure to categorize mismatches, and pointed to social network analysis as a solution. In short, there is a long-standing awareness of scale mismatches in socioecological systems, and there have been several attempts to categorize temporal mismatches. However, the recommendations for resolving mismatches tend to be broad, and only a few specific tools or solutions are available.

We expanded on past work. First, we cast temporal mismatches in socioecological systems in a decisionanalytical framework, recognizing that the problem of conservation interest is the nature of the actions taken by individuals within public decision-making institutions and the responses of individual actors within the social system. As a result, we assumed that solutions could be found in adjusting the time scales of human decision making and action. Second, we delineated where time-scale mismatches could occur within and between components of the public decision-making process, and responses in the socioecological system. We then categorized the mismatches to reveal commonalities across a variety of case studies that at first glance were quite different. Third, we identified tools from the behavioral sciences that recognize and correct for errors and idiosyncrasies in human judgment and decision making related to time, such as discounting future outcomes at rates as from $30 \%$ to $100 \%$ (Frederick et al. 2002) and putting the needs of our current selves over those of our future selves and future generations (Wade-Benzoni 2002; Van Lange et al. 2013) (see Supporting Information for additional discussion of the human tendency toward shortsighted thinking). We then associated these behavioral tools with domains of mismatches to point to concrete solutions that are available based on the type of mismatch identified.Our approach was both inductive and deductive in that we started by identifying common temporal mismatches across a range of conservation-related case studies (Supporting Information). We then developed 


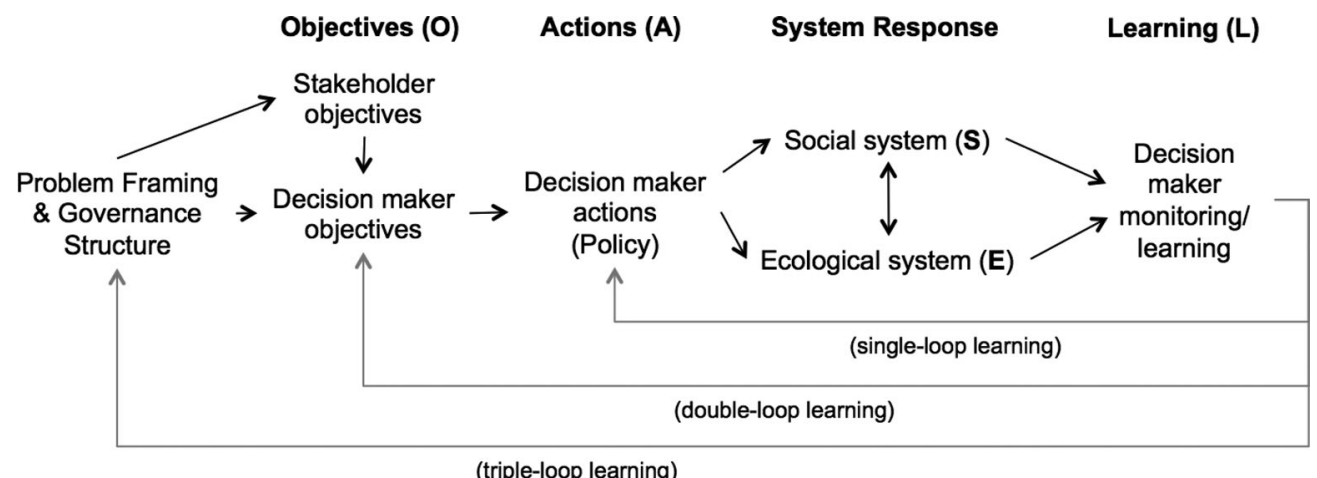

Figure 1. A decision framework for conservation and environmental management with adaptive feedback loops that can be used to modify actions, objectives, and governance structures determined by individual decision makers within public institutions (Pabl-Wostl 2009).

the decision framework to deduce all possible pairs of temporal mismatches (i.e., 15 mismatches) and applied this typology to the case studies. We separately reviewed existing tools from the behavioral sciences and used the case studies to test our ideas about how behavioral interventions might address conservation difficulties.

\section{A Common Typology of Time-Scale Mismatches}

We viewed conservation problems through the lens of public decision making, focusing on 5 elements of a decision framework: the objectives considered by individual decision makers within a public institution; the actions taken by decision makers to achieve those objectives; the social and ecological system responses to the actions taken; and the learning mechanisms used by the decision maker to evaluate whether or not the actions had the intended effect (Fig. 1). The driving force in this framework is a decision maker within a public decisionmaking institution, such as a governmental agency, who articulates management objectives and then compares potential management actions or policies while taking into account uncertainty about consequences and potential trade-offs across objectives. Once implemented, the actions have direct effects on the socioecological system. Individual actors within the social system, in turn, take actions that further affect the ecological system. We focused on individual actors within the social system, not groups (i.e., informal institutions) or other formal institutional actors within the social system who may respond to actions taken within a formal decision-making framework. Although individual actors within the social system are not solely influenced by formal policy and management actions, addressing the mediating role of social or political context and the complexity within the social system is outside of the scope of this paper. The final element occurs when the decision maker has the opportunity to monitor the response of the socioecological system and to use the learning that accrues to adjust actions or policies (single-loop learning), update management objectives or consider new sets of actions (double-loop learning), or change the existing institutional arrangement or governance structure itself (triple-loop learning) (Pahl-Wostl 2009).

Each element in the decision framework (see Fig. 1) has characteristic time scales. The objectives $(\mathrm{O})$ considered by the decision makers have both implicit and explicit time scales, such as the time frame over which ecological responses are evaluated to assess whether or not an objective has been achieved, and the discount rates (i.e., the present value of future benefits) assigned to assess ecological and social outcomes that occur at different points in time (Clark 2010). The temporal aspects of the actions (A) taken by the decision maker include the time it takes to begin implementation, the time over which the actions are implemented, and the interval or intervals at which the actions can be adjusted.

The social system (S) is composed of a variety of actors (e.g., individuals, groups, and other institutions) who are affected by the decision maker's actions and who take action in response, based on their own sets of objectives and their assessments of the problem and the actions proposed. We focused explicitly on individual actors within the social system (e.g., consumers, hunters, ranchers, homeowners, and voters). Although these actors are influenced by a variety of forces within the social system, we focused on 3 time-based challenges: individuals have their own time frames for evaluation and their own discount rates that might differ from those of the decision maker; the actions these individuals take have various lags and durations; and the rate at which these individuals acquire and adapt to information varies. These are specific challenges that can influence the quality of the decisions made in response to formal action by the decision maker, and it is these challenges that might be amenable to time-scale focused behavioral solutions.

The response of ecological systems (E) to management or policy interventions and to the actions of individual actors occurs on time scales driven by system dynamics. 
(For a more detailed discussion of the dynamics within socioecological systems and a framework for identifying the factors driving change within coupled systems, see work by Collins et al. 2010.) These responses might be quite slow (e.g., recovery of top predator fish populations from overfishing), but in other cases, they may be very fast (e.g., spread of invasive species or wildlife diseases). Institutional learning $(\mathrm{L})$ from monitoring programs designed to reduce uncertainty about system states and dynamics has time scales related to frequency of observation, background variability in the ecological system, power to detect change over various spans of time, and frequency of system perturbations.

Time-scale mismatches within and among the decision elements are at the heart of the initial case studies we considered, but our typology lends additional structure by identifying 15 specific types of temporal mismatches (Table 1). The typology is intended to serve as a diagnostic tool to identify where problematic mismatches might occur for a particular conservation problem. The 15 types of mismatches can be grouped into 6 domains based on whether the conflicts occur within or between individual decision makers in the public institution, the individual actors in the social system, or the ecological system.

Six of the time-scale mismatches are within the decision maker's domain (domain 1 in Table 1). For example, a forest management agency may need to manage timber extraction on annual scales while maintaining biodiversity on decadal to century scales, which represents a potential temporal conflict in short- versus long-term objectives (OO), immediate versus future actions (AA), and rates of learning across time (LL). Domain 1 mismatches include mismatches between the decision maker's objectives, actions, and learning. For example, the long-term objective of maintaining ecosystem resilience in ocean fisheries might require drastic reductions in the harvest rate of fish that are socially, economically, and politically unpalatable on short time scales (OA); understanding might arise too slowly to provide adequate feedback on achievement of objectives (OL); and the decision maker might have ineffective mechanisms in place for learning and adaptive management as is often the case in fisheries management (AL) (Mumby et al. 2007).

Three of the time-scale mismatches occur between aspects of the decision maker's domain and individual actors in the social system (domain 2 in Table 1; OS, AS, and LS). In many cases, mismatches arise between decision makers acting on behalf of the public across generations and individuals acting with a narrower focus on the self (vs. others) and on near-term consequences. For example, despite policies within the U.S. Forest Service that support the use of fire as a management tool to promote long-term ecological functioning, reservations from multiple actors within the social system (e.g., short- term risk aversion among fire managers) can delay policy implementation (Wilson et al. 2011).

Three of the mismatches occur between the decision maker's domain and ecosystem dynamics (domain 3 in Table 1). First, the institutional objectives may be impossible to achieve in the desired time frame, relative to the temporal response in the ecological system (OE), as demonstrated by the desire for an immediate end to cyanobacterial blooms in economically critical water bodies despite decadal or even centuries-long retention of nutrients in sediments (Carpenter 2003). Second, the speed of ecological change may outstrip the ability of agencies to develop interventions (AE), as has occurred with the spread of white-nose syndrome in cave-dwelling bat populations in North America (Foley et al. 2011) or in the futile desire to measure the success of 3-year coral reef protection projects in systems where natural processes play out over decades (Bruno \& Selig 2007). Third, important ecological changes may be difficult to detect against the backdrop of noise in the system (LE), as is the case with emerald ash borer (Agrilus planipennis), where the invader's fast rate of spread relative to managers' ability to detect its presence in a location results in the spread outpacing the control (Herms \& McCullough 2014).

The last 3 domains have to do with temporal mismatches within the social system (domain 4 in Table 1 , SS), between the social and ecological system (domain $5, \mathrm{SE}$ ), and within the ecological system (domain 6, EE). Domain 4 mismatches are those that occur within and among the objectives of individual actors in the social system, the rates at which they obtain new information, and the rates at which they act. This domain is similar in scope and complexity to domain 1 but may be particularly amenable to behavioral solutions targeted at individuals acting within a social and political context. Domain 5 mismatches occur when individual actors operate on different time scales than the ecological system, either acting too quickly in response to short-term observations (e.g., misinterpreting short-term changes in the weather as indicative of longer term climate patterns, leading to climate denial [Weber \& Stern 2011]), or failing to perceive and respond to slower shifts in ecological conditions (e.g., failing to adjust agricultural practices in the Great Plains when a multiyear drought occurred after the unusually wet 1920s [Peters et al. 2014]). Domain 6 mismatches occur when different elements of the ecosystem respond to human action at different rates (Hastings 2010). One such example is the case of small predatory groupers (e.g., Cepbalopbolis fulvus) that recover rapidly when fishing pressure is removed relative to large predatory groupers (e.g., Mycteroperca bonaci) that can take decades to recover, at which point they have a strong inhibitory effect on the abundance of smaller groupers (Mumby et al. 2011). Failure to account for the complexities of these temporal interactions can lead to 
Table 1. A typology of time-scale mismatches as delineated by the components of the decision framework in Fig. $1^{a}$

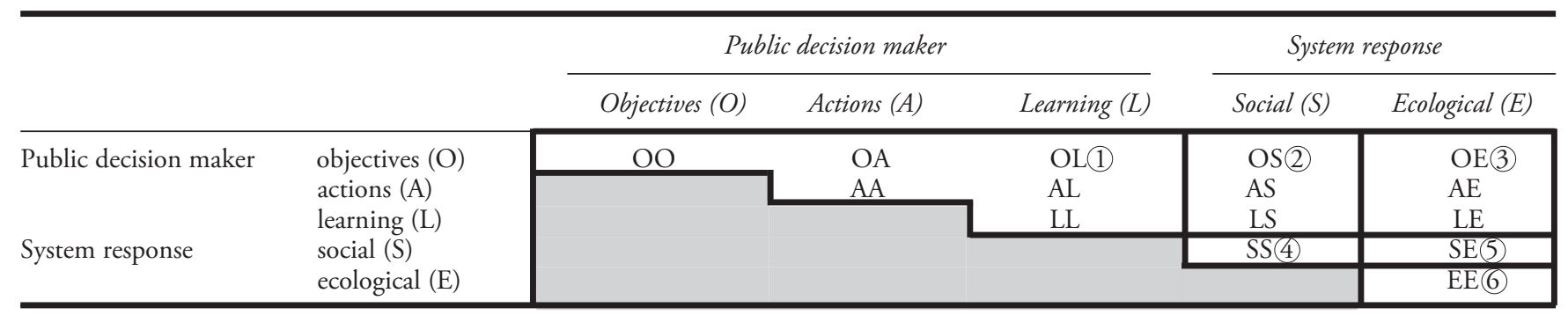

${ }^{a}$ The 15 specific types of mismatches are identified by 2 -letter abbreviations representing the different components of the decision framework (e.g., AS, for actions taken by the decision maker and the response of individual actors in the social system; OS, for objectives of the public decision maker and the response of individual actors in the social system, etc.). These unique combinations fall into 6 domains (numbers 1-6) (1, mismatches within the public decision maker; 2, mismatches between the public decision maker and the social system; 3, mismatches between the public decision maker and the ecological system; 4, mismatches within the social system; 5 , mismatches between the social and the ecological systems; and 6, mismatches within the ecological system).

mistaken predictions of the effects of conservation and management.

\section{Solutions to Time-Scale Mismatches}

Generally speaking, the tools that can be applied to address time-scale issues are technological (engineering based), cognitive (information based), and structural (consequence based) (McKenzie-Mohr 2011; Heberlein 2012). Technological solutions typically bypass the human behavior that is at the root of the problem, focusing instead on modifying ecological systems to suit human time scales. Such solutions are typically put into place when the ecological system is not responding quickly enough or the system is changing too quickly given individual objectives and needs (domains 3 and 5). From a historical perspective, the development of agriculture (e.g., shifting vegetation toward higher yielding annuals) can be interpreted as an attempt to solve a perceived problem using technological solutions. These manipulations have been successful in many respects, but failure to account for time-scale alignment has also led to harmful consequences, such as the eutrophication occurring in water bodies around the globe as a result of large-scale modern agriculture (Carpenter 2003).

We think that the most promising solutions to mismatched time scales can be found in modifying the behavior of individuals given that human behavior is at the root of most conservation problems (Schultz 2011). Cognitive tools change the way information is processed and used in decision making, whereas structural tools change the consequences of an action (in a positive or negative direction). The suite of cognitive and structural tools available has been presented in a variety of publications identifying how best to change behavior to achieve conservation goals (e.g., McKenzie-Mohr 2011; Osbaldiston \& Schott 2011; Clayton et al. 2013). Recommended approaches include, but are not limited to, appealing to existing environmental values (Stern 2000), triggering relevant social cues (Cialdini 2003), and making the intended behavior easy to perform (White \& Simpson 2013). We focused on recommendations that specifically aim to reduce errors in judgment related to how individuals perceive and value time (Supporting Information). These tools have been tested across a variety of contexts, including those related to the environment and conservation (Hardisty et al. 2012).

\section{Cognitive Tools}

Decades of research in the behavioral sciences indicate that an information deficit approach to changing behavior will be insufficient (Simon 1990). In some contexts, more knowledge can actually decrease support for a conservation effort by increasing the ability of individuals to counterargue and defend a strongly held value or cultural identity (Kahan et al. 2012). To be effective, information aimed at changing the way an individual thinks about a problem, as a means to changing behavior, must be carefully framed (Chong \& Druckman 2007). In the context of mismatched time scales, strategic framing can be used when it is difficult or impossible to change ecological time scales (e.g., fish reproductive cycles) or the tangible consequences (e.g., changing the price of fish). Specifically, framing can help increase alignment within the institution or social system (domains 1 and 4) and bring institutional decision makers into alignment with the time scales of socioecological systems (domains 2 and 3) and individual actors into alignment with the time scales of ecological system (domain 5). Generally, this involves changing the perceived value of costs and benefits over time to motivate action. Some potential framing tools to consider include presenting large-magnitude effects and trends over time, loss framing, and appealing to high-level goals. For example, people generally make more far-sighted decisions when considering larger magnitude costs and benefits (Thaler 1981). As a result, reporting the total expected number of ash trees (Fraxinus spp.) to be killed by emerald 
ash borer may more effectively encourage immediate reduction in firewood movement than reporting annual statistics. People also respond differently to single outcomes versus trends over time, preferring improving trends rather than declining even if the same set of average returns is presented (Loewenstein \& Prelec 1993). For example, fishers may respond more positively to a fish restoration program in the present when the quotas are presented as an increasing allowable catch over time compared with a single total over that same period. In terms of loss framing, people make judgments with respect to a reference point (i.e., the present, the past, and the future), and are generally more motivated by losses than gains (Tversky \& Kahneman 1991). As a result, presenting fire as a forest management tool to restore a forest that was previously functioning (i.e., recovering a loss) is more acceptable to stakeholders than describing it as a tool to achieve an improvement over the present (i.e., a gain) (Wilson et al. 2012). Finally, people tend to construe more temporally distant events abstractly (i.e., focusing on why it happened or will happen) rather than concretely (i.e., focusing on what is happening). This typically leads to behavior more consistent with long-term values and goals (Trope \& Liberman 2003). Therefore, if the goal is to encourage fishers to pursue long-term, abstract goals (e.g., sustainability) relative to short-term, concrete concerns (i.e., annual profit), one should focus their attention on the state of the fishery in 10 years, as opposed to the upcoming year.

A second set of cognitive tools comes from decision structuring and multicriteria decision analysis, which inform decision making through a deliberate assessment of the trade-offs across time (Gregory et al. 2012). To permit explicit consideration of intertemporal trade-offs, the description of the decision context should include both the frequency with which management decisions might be revised and the time span over which the consequences of management actions will be evaluated. For example, management plans to restore old-growth characteristics in deciduous forests might be revised every 10 years, but the results of altered management will not be fully realized for decades or even centuries. To choose among management options that impose costs and deliver benefits at different future times, the ways that different actors discount the future must be represented explicitly. For example, the heads of land management agencies may be most concerned about the near future, the time frame most relevant to evaluating their own job performance, whereas members of environmental groups may be most focused on the long-term future, when the fate of endangered plant and animal species will become most evident. Some suggest using different time horizons and discount rates for financial versus ecological impacts (Rout \& Walshe 2013) to account for empirical evidence that people discount financial costs and benefits at a more or less exponential rate but nonfinancial costs and benefits at a nearly hyperbolic rate (i.e., rapid discounting in the very short term and a much slower increase in discounting in the distant future). Such an approach would capture the time scales of both the land management agencies and the environmental groups in the same analytic model.

\section{Structural Tools}

Although cognitive tools such as strategic framing and decision analysis hold great promise at improving decision making by changing the way individuals perceive and value time, structural tools (e.g., incentives) may be a more direct means of preventing short-sighted behavior (Schultz 2011; Heberlein 2012; Clayton et al. 2013). Such tools work by changing the social, political, or environmental context in which decisions are made, essentially altering the consequences of an action (Thaler \& Sunstein 2009; Heberlein 2012). Structural tools can be used to increase alignment between the decision maker in an institution setting management policy and the individual actors in the system (domain 2). They can also be useful to increase alignment within the institution or social system (domains 1 and 4) or to reconcile mismatches between institutional decision makers or individual actors and the ecological system (domains 3 and 5). Generally, this involves incentivizing individuals to match the time scale of the ecological system. Some relevant structural tools to consider include legal prohibitions, taxes and subsidies, temporal restructuring, and behavioraleconomic nudges. Legal prohibitions are enacted when the right action is clear and the wrong action is obviously harmful. Many countries have laws (e.g., the Endangered Species Act in the United States) that directly and in some cases indirectly prevent harm to a species in the short term to achieve long-term objectives. Temporal aspects of conservation problems are sometimes acknowledged explicitly in these laws. Taxes and subsidies are used when an action is desirable but not deemed appropriate for legal prohibition. For example, government payments may be provided per acre to offset the short-term cost of taking land out of agricultural production to promote long-term wildlife habitat or protect water quality (Secchi et al. 2008). Temporal restructuring is used to better align time scales through the creation of new financial or legal contracts. Conservation easements, under which landowners receive immediate tax breaks in return for restricting some uses of their property, have been successful in retaining undeveloped land in areas where development pressure is high. Heirs to the property must continue the easement or repay the reduced taxes. Thus, individual actors receive immediate financial incentives to promote long-term conservation benefits, solving the time-scale mismatch.

Finally, behavioral-economic nudges are used to guide people toward better choices that result in long-term benefits while not eliminating the freedom of choice 
in the present. These can include the framing tools discussed previously and other tools such as binding precommitments, default settings, channel factors, and broad choice bracketing. Specifically, people will more readily agree to a future commitment of time or money than an immediate contribution, due to discounting. The key is to ensure that commitments to future actions are binding (Thaler \& Benartzi 2004). For example, a policy might encourage farmers to commit to adjusting their fertilizer application practices starting in 3 years (rather than immediately) to reduce impacts on water quality and aquatic species. People are also more likely to stick to a default than opt in to an alternative option (Johnson \& Goldstein 2003). Many U.S. states use check boxes on tax returns to raise money for programs such as wildlife conservation. These typically require a taxpayer to opt in; changing the procedure so that the taxpayer needed to check a box to opt out would be an example of making conservation action the default. People are also more likely to act when it is easy and convenient to do the right thing (Leventhal et al. 1965). The tax check boxes mentioned above are an example of making it easy for people to do the right thing. Finally, people tend to make more deliberate choices when considering a large set of choices as opposed to choices considered in isolation (Read et al. 2000). If fire insurance on homes in the wildland-urban interface were offered on a 5- or 10-year basis, rather than annually, so that the premium reduction for fire-wise retrofits became substantial, homeowners might think about fire management on a longer time scale and more readily undertake modifications to their houses and landscapes.

Together, cognitive and structural tools can be brought to bear on the different domains of time-scale mismatches by targeting the temporally biased behavior of individuals within decision-making institutions and within the broader social system. In so doing, conservation professionals can overcome some of the decision-making challenges that are the result of "boundedly rational" humans operating in a complex and temporally dynamic environment (Simon 1990). We expect that these tools might be used in combination, for example, motivating individuals to increase invasive species control on their lands by highlighting the legacy they want to leave for their family and community and pairing this action with technical assistance or subsidies that make the choice to conserve easier. These are not mutually exclusive approaches, and our list of example tools within the categories is not exhaustive.

\section{Synthesis and Prospectus}

We showed that poor alignment in time scales is a common thread that helps explain why many complex conservation challenges are difficult to solve. We identified a set of behavioral tools aimed at resolving time-scale challenges in decision making and suggested that many management challenges could be resolved if the right time-scale issues were identified and appropriate behavioral solutions employed to either change the way individuals perceive and value time or alter the consequences of (often short-sighted) behavior. Many of the tools we described have been tested in environmental contexts (e.g., using large-magnitude, broad-bracket frames to increase the attractiveness of fuel-efficient vehicles) (Camilleri \& Larrick 2014) and applying decision-aiding techniques to find a balance between long-term coastal ecosystem conservation and short-term coastal development under rising sea levels (Mills et al. 2014). However, explicitly testing how these tools solve temporal mismatches within conservation contexts has received less attention. Wider testing of these solutions, and long-term evaluation measures that assess not just behavioral changes but also associated changes in ecological systems, will provide further understanding of the advantages and limitations of our typology and recommended solutions.

\section{Acknowledgments}

This work was supported by the National SocioEnvironmental Synthesis Center (SESYNC) under funding received from the National Science Foundation DBI1052875 with additional support from University of Maryland, University of Maryland Center for Environmental Science, and Resources for the Future. This work was also supported by an NSF Behavioral and Cognitive Sciences grant through the Dynamics of Coupled Natural and Human Systems Program (BCS-1114934), as well as UC AES project CA-D-ESP-2163-H and NSF grant DEB-1009957. We are grateful to $\mathrm{F}$. Johnson and 2 anonymous reviewers for their thoughtful comments. Any use of trade, product, or firm names is for descriptive purposes only and does not imply endorsement by the U.S. Government.

\section{Supporting Information}

Case studies of time-scale mismatches (Appendix S1) and a review of behavioral science concepts useful for understanding how individuals perceive time (Appendix S2) are available online. The authors are solely responsible for the content and functionality of these materials. Queries (other than absence of the material) should be directed to the corresponding author.

\section{Literature Cited}

Bruno JF, Selig ER. 2007. Regional decline of coral cover in the IndoPacific: timing, extent, and subregional comparisons. PLOS ONE 2:(e711). 
Camilleri AR, Larrick RP. 2014. Metric and scale design as choice architecture tools. Journal of Public Policy \& Marketing 33:108125.

Carpenter SR. 2003. Regime shifts in lake ecosystems: pattern and variation. International Ecology Institute, Luhe, Germany.

Chong D, Druckman JN. 2007. Framing theory. American Review of Political Science 10:103-126.

Cialdini RB. 2003. Crafting normative messages to protect the environment. Current Directions in Psychological Science 12:105109.

Clark CW. 2010. Mathematical bioeconomics: the mathematics of conservation. John Wiley \& Sons, Hoboken, NJ.

Clayton S, Litchfield C, Geller ES. 2013. Psychological science, conservation, and environmental sustainability. Frontiers in Ecology and the Environment 11:377-382.

Collins SL, Carpenter SR, Swinton SM, Orenstein DE, Childers DL, Gragson TL, Grimm NB, Grove JM, Harlan SL, Kaye JP. 2010. An integrated conceptual framework for long-term social-ecological research. Frontiers in Ecology and the Environment 9:351-357.

Cumming GS, Cumming DHM, Redman CL. 2006. Scale mismatches in social-ecological systems: causes, consequences, and solutions. Ecology and Society 11(1): 14 .

Foley J, Clifford D, Castle K, Cryan P, Ostfeld RS. 2011. Investigating and managing the rapid emergence of white-nose syndrome, a novel, fatal, infectious disease of hibernating bats. Conservation Biology 25:223-231.

Folke C, Pritchard L, Berkes F, Colding J, Svedin U. 2007. The problem of fit between ecosystems and institutions: ten years later. Ecology and Society 12:30.

Frederick S, Loewenstein G, O'Donoghue T. 2002. Time discounting and time preference: a critical review. Journal of Economic Literature 40:351-401.

Gregory R, Dieckmann N, Peters E, Failing L, Long G, Tusler M. 2012. Deliberative disjunction: expert and public understanding of outcome uncertainty. Risk Analysis 32:2071-2083.

Guerrero AM, McAllister R, Corcoran J, Wilson KA. 2013. Scale mismatches, conservation planning, and the value of social-network analyses. Conservation Biology 27:35-44.

Gunderson LH. 2001. Panarchy: understanding transformations in human and natural systems. Island Press, Washington, D.C.

Hardisty DJ, Orlove B, Krantz DH, Small AA, Milch KF, Osgood DE. 2012. About time: an integrative approach to effective environmental policy. Global Environmental Change 22:684-694.

Hastings A. 2010. Timescales, dynamics, and ecological understanding 1. Ecology 91:3471-3480.

Heberlein TA. 2012. Navigating environmental attitudes. Oxford University Press, New York, NY.

Herms DA, McCullough DG. 2014. Emerald ash borer invasion of North America: history, biology, ecology, impacts, and management. Annual Review of Entomology 59:13-30.

Holling CS. 2001. Understanding the complexity of economic, ecological, and social systems. Ecosystems 4:390-405.

Johnson EJ, Goldstein D. 2003. Do defaults save lives? Science 302:1338-1339.

Kahan DM, Peters E, Wittlin M, Slovic P, Ouellette LL, Braman D, Mandel G. 2012. The polarizing impact of science literacy and numeracy on perceived climate change risks. Nature Climate Change 2:732735.

Leventhal H, Singer R, Jones S. 1965. Effects of fear and specificity of recommendation upon attitudes and behavior. Journal of Personality and Social Psychology 2:20-29.

Loewenstein GF, Prelec D. 1993. Preferences for sequences of outcomes. Psychological Review 100:91-108.

McKenzie-Mohr D. 2011. Fostering sustainable behavior: an introduction to community-based social marketing. New Society Publishers, Gabriola Island, BC, Canada.
Mills M, Nicol S, Wells JA, Lahoz-Monfort JJ, Wintle B, Bode M, Wardrop M, Walshe T, Probert WJM, Runge MC. 2014. Minimizing the cost of keeping options open for conservation in a changing climate. Conservation Biology 28:646-653.

Mumby PJ, Hastings A, Edwards HJ. 2007. Thresholds and the resilience of Caribbean coral reefs. Nature 450:98-101.

Mumby PJ, Steneck RS, Edwards AJ, Ferrari R, Coleman R, Harborne AR, Gibson JP. 2011. Fishing down a Caribbean food web relaxes trophic cascades. Marine Ecology Progress Series 445:13-24.

Osbaldiston R, Schott JP. 2011. Environmental sustainability and behavioral science: meta-analysis of proenvironmental behavior experiments. Environment and Behavior 44(2):257-299.

Ostrom E. 1990. Governing the commons: the evolution of institutions for collective action. Cambridge University Press, Cambridge, United Kingdom.

Pahl-Wostl C. 2009. A conceptual framework for analysing adaptive capacity and multi-level learning processes in resource governance regimes. Global Environmental Change 19:354-365.

Peters DPC, Loescher HW, SanClements MD, Havstad KM. 2014. Taking the pulse of a continent: expanding site-based research infrastructure for regional- to continental-scale ecology. Ecosphere 5:art29.

Read D, Loewenstein G, Rabin M, Keren G, Laibson D. 2000. Choice bracketing. Pages 171-202 in Fischhoff B, Manski CF, editors. Elicitation of preferences. Springer, Norwell, MA.

Rout TM, Walshe T. 2013. Accounting for time preference in management decisions: an application to invasive species. Journal of Multi-Criteria Decision Analysis 20:197-211.

Schultz P. 2011. Conservation means behavior. Conservation Biology 25:1080-1083.

Secchi S, Tyndall J, Schulte LA, Asbjornsen H. 2008. Raising the stakes: high crop prices and conservation. Journal of Soil and Water Conservation 63:68A-73A

Simon H. 1990. Invariants of human behavior. Annual Review of Psychology 41:1-19.

Stern PC. 2000. Toward a coherent theory of environmentally significant behavior. Journal of Social Issues 56:407-424.

Thaler R. 1981. Some empirical evidence on dynamic inconsistency. Economics Letters 8:201-207.

Thaler RH, Benartzi S. 2004. Save More Tomorrow ${ }^{\mathrm{TM}}$ : using behavioral economics to increase employee saving. Journal of Political Economy 112:S164-S187.

Thaler RH, Sunstein CR. 2009. Nudge: improving decisions about health, wealth and happiness. Penguin Books, New York.

Trope Y, Liberman N. 2003. Temporal construal. Psychological Review 110:403-421.

Tversky A, Kahneman D. 1991. Loss aversion in riskless choice: a reference-dependent model. The Quarterly Journal of Economics 106:1039-1061.

Van Lange PAM, Joireman J, Parks CD, Van Dijk E. 2013. The psychology of social dilemmas: a review. Organizational Behavior and Human Decision Processes 120:125-141.

Wade-Benzoni KA. 2002. A golden rule over time: reciprocity in intergenerational allocation decisions. Academy of Management Journal 45:1011-1028.

Weber EU, Stern PC. 2011. Public understanding of climate change in the United States. American Psychologist 66:315-328.

White K, Simpson B. 2013. When do (and don't) normative appeals influence sustainable consumer behaviors? Journal of Marketing 77:78-95.

Wilson RS, Ascher TJ, Toman E. 2012. The importance of framing for communicating risk and managing forest health. Journal of Forestry 110:337-341.

Wilson RS, Winter PL, Maguire LA, Ascher TJ. 2011. Managing wildfire events: risk-based decision making among a group of federal fire managers. Risk Analysis 31:805-818. 